\title{
Produtividade do repolho utilizando cobertura morta e diferentes intervalos de irrigação com água moderadamente salina ${ }^{1}$
}

\author{
José F. de Carvalho ${ }^{2}$, Abelardo A. A. Montenegro² Tales M. Soares ${ }^{2}$, \\ Ênio F. de F. e Silva² \& Suzana M. G. L. Montenegro ${ }^{3}$
}

\begin{abstract}
RESU MO
0 manejo da irrigação em áreas sob escassez hídrica é imperativo para o incremento da eficiência do uso da água, particularmente em áreas susceptíveis a salinização e a elevadas demandas atmosféricas. N este estudo avaliou-se o efeito da cobertura morta e de interval os de irrigação utilizando-se água moderadamente salina sobre a produtividade do repolho e sobre suas variáveis relacionadas, em vale aluvial no semiárido. 0 delineamento experimental foi em blocos casualizados em esquema fatorial $3 \times 2$, com 4 repetições, mediante a aplicação de intervalos de irrigação de 12, 24 e 48 h, com utilização de uma fração de lixiviação de $20 \%$, e presença ou ausência de cobertura morta sobre o solo. Verificou-se que as produtividades foram afetadas pelos intervalos de irrigação e pela presença da cobertura morta. A máxima eficiência uso da água foi obtida aplicando-se o intervalo de irrigação de $12 \mathrm{~h}$ com cobertura morta, correspondendo a $110,49 \mathrm{Mg} \mathrm{ha}^{-1} \mathrm{~mm}^{-1}$, em consequência da menor variação da umidade ao longo do experimento. A relevância da cobertura morta ficou evidenciada para o tratamento com intervalo de irrigação de $48 \mathrm{~h}$, tendendo a controlar as perdas de umidade e manter a produtividade do repolho.
\end{abstract}

Palavras-chave: semiárido, manejo da irrigação, agricultura familiar, Brassica oleraceae

\section{Cabbage yield using mulching and different irrigation intervals with moderately saline water}

\begin{abstract}
The irrigation management in areas under water scarcity is imperative to increase the water use efficiency particularly in areas with salinization risk and high atmospheric demands. In this study, effect of mulching and irrigation intervals was evaluated using moderately saline water on cabbage yield and on its related variables in an alluvial valley in the semiarid. The experimental design was in random blocks using a 3 $\times 2$ factorial scheme, with 4 replications, adopting irrigation application intervals of 12, 24 and $48 \mathrm{~h}$, and a leaching fraction of $20 \%$, and considering mulching presence or absence on the soil. It was verified that productivities have been affected by the irrigation interval and by mulching. The maximum water use efficiency was obtained with irrigation frequency of $12 \mathrm{~h}$ and mulching adoption, corresponding to $110.49 \mathrm{Mg} \mathrm{ha}^{-1} \mathrm{~mm}^{-1}$, associated to a lower soil moisture variation along the experiment. Mulching relevance was highlighted for the irrigation interval equal to $48 \mathrm{~h}$, contributing to control moisture losses, and to keep cabbage yield.
\end{abstract}

Key words: semiarid, irrigation management, communal farming, Brassica oleraceae

\footnotetext{
${ }^{1}$ Parte da Dissertação de Mestrado do primeiro autor, apresentada à U niversidade Federal Rural de Pernambuco, U FRPE.

2 UFRPE, Rua Dom Manoel de Medeiros s/n, Dois Irmãos, CEP 52171-900 Recife, PE. E-mail: carvalho.jcarvalho20@gmail.com; abelardo.montenegro@yahoo.com.br;talesmiler@gmail.com;enio.silva@dtr.ufrpe.br

3 UFPE, Rua Acadêmico Hélio Ramos, s/n, Cidade Universitária, CEP 50670-901, Recife, PE. E-mail: suzanam@ufpe.br
} 


\section{INTRODUÇÃO}

Dentre as variedades botânicas da espécie Brassica oleracea, o repolho é a de maior expressão econômica na produção mundial e brasileira (Brackmann et al, 2003). Esta cultura é exigente em água, requerendo elevadas umidades no solo durante todo o ciclo. Geralmente sua produtividade é superior a $50 \mathrm{Mg} \mathrm{ha}^{-1}$, quando em condições hídricas e de temperatura adequada, entre 15 e $20^{\circ} \mathrm{C}$ (Filgueira, 2007). Destaca-se, ainda, em termo de valor alimentício, o alto teor de vitamina $\mathrm{C}$, fornecendo também vitaminas $\mathrm{B} 1, \mathrm{~B} 2, \mathrm{E}, \mathrm{K}$ e sais minerais, sobretudo cálcio e fósforo, além de apresentar fácil digestibilidade (Filgueira, 2007; Lédo et al., 2000). Filgueira (2007) destaca a grande importância dessa cultura, por empregar elevada mão-de-obra, sendo cultivada essencialmente por agricultores familiares.

Fracaro et al. (1999) avaliaram cultivares de repolho no Rio Grande do Sul utilizando irrigação por aspersão e obtiveram produção de $31,67 \mathrm{Mg} \mathrm{ha}^{-1}$, cabeças com massa fresca média de $1270 \mathrm{~g}$ e índice de formato de 0,77, enquanto Moura et al. (2006), pesquisando o híbrido Astrus em São Luís sob irrigação por aspersão obtiveram produtividades de 13,00 $\mathrm{Mg} \mathrm{ha}^{-1}$, independente da presença ou da ausência da cobertura morta e de 7,50 $\mathrm{Mg} \mathrm{ha}^{-1}$ e 15,00 $\mathrm{Mg} \mathrm{ha}^{-1}$ na ausência e presença de cobertura morta respectivamente, utilizando irrigação por sulcos, com massa fresca média de 449,66 g e índice de formato de 0,85 . Em clima semiárido, Santiago (2002) obteve produtividade média de $10,15 \mathrm{Mg} \mathrm{ha}^{-1}$, cultivando o híbrido de repolho Midori, no mesmo local do presente experimento, com microaspersão, e 20\% de fração de lixiviação.

Imtiyaz et al. (2000) avaliaram o efeito de diferentes lâminas de irrigação na produtividade do repolho e obtiveram os melhores rendimentos com lâminas de irrigação, correspondendo a $80 \%$ da evapotranspiração da cultura estimada a partir do Tanque Classe A.

O uso de cobertura morta no solo é uma prática recomendada, em particular nas regiões semiáridas, contribuindo para a melhoria do desempenho das culturas, redução das perdas de água do solo e redução da erosão superficial (Souza et al., 2008a). Moraes et al. (2007), cultivando repolho em Dourados, utilizaram 0 e 6,5 $\mathrm{Mg} \mathrm{ha}^{-1}$ de cama-de-frango como cobertura, obtendo produtividades significativamente maiores com sua utilização. Queiroga et al. (2002) obtiveram produção estatisticamente superior com a adoção de $13 \mathrm{Mg} \mathrm{ha}^{-1}$ de cobertura do solo, com palha de carnaúba, no cultivo de pimentão. Já Mulumba \& Lal (2008) estudaram o efeito de diferentes densidades de cobertura morta (palha de trigo) nas propriedades físicas de um solo não cultivado e obtiveram valores máximos de retenção de umidade com cobertura de densidade de $8 \mathrm{Mg} \mathrm{ha}^{-1}$.

Souza et al. (2008a), cultivando cenoura irrigada por microaspersão na área do presente trabalho, estudaram o efeito da cobertura morta de restolhos de feijão com densidade de 9 $\mathrm{Mg} \mathrm{ha}^{-1}$ e observaram valores estatisticamente superiores para a maioria das umidades nas profundidades de 20 e $40 \mathrm{~cm}$, quando se adotou cobertura morta. Do mesmo modo, Souza et al. (2008b), pesquisando os efeitos da mesma cobertura sobre a salinidade, RAS e PST, no cultivo de cenoura, também constataram valores estatisticamente menores quando a cobertura foi adotada.

As frequências de irrigação possuem papel importante no controle da salinidade, segundo Rhoades et al. (1974). Evidências experimentais permitem recomendar a redução do intervalo de irrigação quando se utiliza água salina, visando manter elevado o potencial mátrico e osmótico. Por outro lado, turnos de rega reduzidos aumentam os custos operacionais, particularmente na agricultura familiar. Lima et al. (2006) cultivaram pimentão com água moderadamente salina, adotando frequências diárias e de dois dias, na presença e ausência de cobertura morta. Os autores obtiveram massa de frutos significativamente superior quando se adotou turno de rega diário com cobertura morta de $1 \mathrm{Mg} \mathrm{ha}^{-1}$ de palhada de milho, lâmina correspondente a $80 \%$ da evapotranspiração do pimentão, sem provocar aumento da salinidade. Montenegro et al. (2010), na área de estudo do presente experimento e através do modelo SALTMED (Ragab, 2002) com água moderadamente salina, verificaram que a adoção de lâmina deficitária ( $80 \%$ ETc) não produziu alteração significativa na produtividade do repolho. Adicionalmente, a adoção de turnos de rega de 1,2 e 3 dias não provocou alteração significativa na salinidade do solo, não acarretando decréscimo de produtividade.

A utilização de água de qualidade inferior pode comprometer o desenvolvimento do repolho. Maas (1986) destaca que o repolho é moderadamente sensível à salinidade e sugere o valor de $1,0 \mathrm{dS} \mathrm{m}^{-1}$ para o limiar de condutividade elétrica do extrato de saturação, a partir do qual ocorre decréscimo de 9,7\% na produtividade, para cada aumento unitário na condutividade elétrica.

Neste sentido, o presente trabalho foi realizado com o objetivo de avaliar a eficiência do uso da água e a produtividade do híbrido de repolho Midori em Neossolo Flúvico, sob diferentes intervalos de irrigação e adoção de cobertura morta, aplicando-se água moderadamente salina, em clima semiárido.

\section{Material E MÉTODOS}

\section{Área de estudo}

O estudo foi desenvolvido em lote experimental da Fazenda Nossa Senhora do Rosário, Pesqueira, PE, situada em vale aluvial na Região Agreste do Estado de Pernambuco, distando $230 \mathrm{~km}$ de Recife e $613 \mathrm{~m}$ acima do nível do mar. As coordenadas geográficas são: 8 34' 17" S e 37 1' 20" W (Souza et al., 2008a). A área experimental possui estação climatológica completa. No período de estudo, de janeiro a março de 2008, foram registrados valores de temperatura do ar entre 18,6 e $33,2^{\circ} \mathrm{Ce}$ precipitação total de $268 \mathrm{~mm}$. As profundidades do nível do lençol freático local, nos meses de janeiro, fevereiro e março de 2008, foram de 2,72, 2,85 e 2,32 m, respectivamente, e a condutividade elétrica da água de irrigação, igual a 1,10, 1,25 e $1,01 \mathrm{dS} \mathrm{m}^{-1}$, respectivamente.

\section{Preparo do solo e delineamento experimental}

Cultivou-se repolho em blocos ao acaso, em esquema fatorial 3 x 2, com 4 blocos de $30 \mathrm{~m}$ de comprimento e $10 \mathrm{~m}$ de largura. 
Os tratamentos primários foram constituídos de três intervalos de irrigação (12, 24 e 48 h), e os tratamentos secundários foram presença e ausência de cobertura morta, com densidade de 13 $\mathrm{Mg} \mathrm{ha}^{-1}$, totalizando 6 tratamentos, com 4 repetições. A dimensão total da área experimental foi de $60 \mathrm{~m} \mathrm{x} 30 \mathrm{~m}$, com blocos dispostos no sentido transversal da área. Cada tratamento possuía uma área útil de 1 x $9 \mathrm{~m}$, sendo eles: COMI1intervalo de irrigação de 12 h com cobertura morta; COMI2intervalo de irrigação de $24 \mathrm{~h}$ com cobertura morta; COMI3intervalo de irrigação de 48 h com cobertura morta; SEMI1intervalo de irrigação de $12 \mathrm{~h}$ sem cobertura morta; SEMI2intervalo de irrigação de $24 \mathrm{~h}$ sem cobertura morta e SEMI3intervalo de irrigação de $48 \mathrm{~h}$ sem cobertura morta. Para estimativa das umidades ao longo do período de cultivo, somou-se, separadamente, cada tratamento em todos os blocos, realizando-se uma média de todo o período, com o objetivo de quantificar a percentagem de variação entre tratamentos.

\section{Solo e clima}

O clima do local é classificado, segundo Köppen, como BShw' semiárido quente, caatinga hiperxerófila. A média anual da umidade relativa do ar é de $73 \%$ e a velocidade média do vento é de $2,5 \mathrm{~m} \mathrm{~s}^{-1}$ (Santiago et al., 2004). A precipitação média anual na região é de $730 \mathrm{~mm}$ e a temperatura média é de $24,8^{\circ} \mathrm{C}$, sendo a evapotranspiração potencial anual de cerca de $1680 \mathrm{~mm}$ (Montenegro \& Montenegro, 2006). O soloé caracterizado como Neossolo Flúvico. As características granulométricas do lote estudado são: camada de 0-20 cm: densidade global $1,63 \mathrm{~kg} \mathrm{dm}^{-3}$, areia grossa 81,35 $\mathrm{g} \mathrm{kg}^{-1}$; areia fina 354,01 $\mathrm{g} \mathrm{kg}^{-1}$; silte 427,93 $\mathrm{g} \mathrm{kg}^{-1}$; argila 136,72 $\mathrm{g} \mathrm{kg}^{-1}$; camada de 20-40 cm: densidade global 1,67 $\mathrm{kg} \mathrm{dm}^{-3}$, areia grossa $105,09 \mathrm{~g} \mathrm{~kg}^{-1}$; areia fina $328,48 \mathrm{~g} \mathrm{~kg}^{-1}$; silte $441,62 \mathrm{~g} \mathrm{~kg}^{-1} \mathrm{e}$ argila $128,41 \mathrm{~g} \mathrm{~kg}^{-1}$. Tal textura caracteriza solos francos, conforme triângulo textural da EMBRAPA (1997). Determinaram-se, experimentalmente, as curvas de retenção de água no solo para as camadas de 0-20 e 20-40 cm, ajustadas pelo modelode Genuchten (1980) (Figura 1).

\section{Sistema e manejo de irrigação}

O sistema por microaspersão utilizado possuía tubulação de sucção de $75 \mathrm{~mm}$, uma linha adutora e três linhas de derivação com comprimento de $30 \mathrm{~m}$ cada uma e diâmetro de $50 \mathrm{~mm}$,

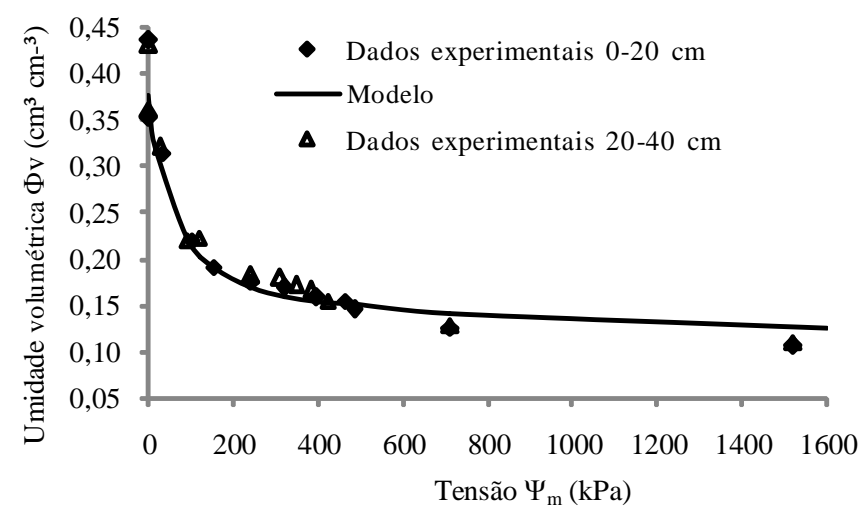

Figura 1. Curva de retenção de umidade do solo na camada de 0-40 cm, ajustada segundo o modelo de Genuchten (1980) equidistantes de $18 \mathrm{~m}$. Cada linha de derivação possuía 24 saídas conectadas a mangueiras de polietileno de $16 \mathrm{~mm}$, dotadas de manômetro e registro.

O espaçamento entre linhas laterais era de $2,73 \mathrm{~m}$ e, entre emissores, de $3 \mathrm{~m}$. O microaspersor era da marca Carborundum, diâmetro igual a $1 \mathrm{~mm}$ e diâmetro molhado igual a $6 \mathrm{~m}$, com vazão de 54,26 L h ${ }^{-1}$ e pressão média de serviço de $213,9 \mathrm{kPa}$. Tal sistema gerava uma intensidade de precipitação de $6,03 \mathrm{~mm}$ $\mathrm{h}^{-1}$ e cobertura de $100 \%$. Foram instalados 264 emissores na área.

A precipitação total no período de cultivo foi de $268 \mathrm{~mm}$, sendo que $170 \mathrm{~mm}$ se concentraram na última semana antes da colheita e os $98 \mathrm{~mm}$ restantes ocorreram nos dois primeiros estádios de desenvolvimento do repolho. As lâminas de irrigação adotadas foram baseadas na evapotranspiração da cultura (ETc), estimada a partir de leituras diárias em Tanque Classe "A", utilizando-se coeficiente de tanque de acordo com condições locais de vento, umidade relativa e bordadura, igual a 0,75 , e coeficiente de cultivo $(\mathrm{Kc})$, segundo Doorenbos \& Kassan (1979). Para o intervalo de $12 \mathrm{~h}$ fracionou-se a ETc de $24 \mathrm{~h}$ em duas, para o intervalo de $24 \mathrm{~h}$ aplicou-se a ETc diária, enquanto, para o intervalo de $48 \mathrm{~h}$ foram somadas as ETcs de dois dias consecutivos. Entretanto, salienta-se que os intervalos de irrigação permaneceram iguais e aplicados duas vezes ao dia para todos os tratamentos, até o décimo quinto dia após transplante (DAT).

A água utilizada na irrigação da área experimental era captada de poço Amazonas e classificada como moderadamente salina (de acordo com classificação proposta por Ayers \& Westcot (1991), com condutividade elétrica média 1,89 dS m ${ }^{-1}$. A razão de adsorção de sódio RAS era de 8,99 $\left(\text { mmol }_{\mathrm{c}} \mathrm{L}^{-1}\right)^{-0,5}$ e o pH de 7,39. Calcularam-se as lâminas de irrigação dos tratamentos foram calculadas adotando-se uma fração de lixiviação de $20 \%$, a qual foi calculada levando-se em consideração a equação de Rhoades (1974), expressa como:

$$
\mathrm{FL}=\frac{\mathrm{CEa}}{5 \mathrm{CEes}-\mathrm{CEa}}
$$

em que:

FL - fração de lixiviação mínima necessária para controlar os sais dentro do limite de tolerância da cultura;

$\mathrm{CEa}$ - salinidade da água de irrigação, $\mathrm{dS} \mathrm{m} \mathrm{m}^{-1}$;

CEes - Salinidade limiar do extrato de saturação do solo, $\mathrm{dS} \mathrm{m}^{-1}$.

A CEes média do solo medida em 24 pontos no lote experimental, foi de $1,12 \mathrm{dS} \mathrm{m}^{-1}$ no início do experimento.

No cálculo do tempo de aplicação das lâminas, foram considerados os resultados de teste do sistema de irrigação, particularmente quanto à eficiência de aplicação do sistema $(84,86 \%)$.

\section{Condução do experimento}

O preparo da área experimental consistiu em operação de aração e gradagem mecanizada. Utilizou-se a cultivar de repolho 'Midori', com semeadura manual em um canteiro de 1 x 15 m. Para o transplante das mudas, aos 37 dias após a semeadura 
Tabela 1. Análise de fertilidade do solo na camada de 0 a $20 \mathrm{~cm}$

\begin{tabular}{|c|c|c|c|c|c|c|c|c|c|c|c|c|c|}
\hline $\mathrm{pH}$ & $\mathbf{P}$ & $\mathrm{Ca}$ & $\mathrm{Mg}$ & $\mathrm{Na}$ & $\mathrm{K}$ & Al & $\mathrm{H}$ & 5 & CTC & V & $\mathrm{N}$ & $\mathrm{CO}$ & MO \\
\hline $\mathrm{H}_{2} \mathrm{O}$ & $\mathrm{mg} \mathrm{dm}^{-3}$ & \multicolumn{8}{|c|}{$\mathrm{cmol}_{\mathrm{c}} \mathrm{dm}^{-3}$} & $\%$ & Dag kg ${ }^{-1}$ & \multicolumn{2}{|c|}{$\mathrm{g} \mathrm{kg}^{-1}$} \\
\hline 7,60 & 105 & 3,95 & 2,30 & 1,00 & 0,30 & 0,00 & 0,82 & 7,6 & 8,4 & 90 & 0,16 & 0,60 & 18,27 \\
\hline
\end{tabular}

orrânico; MO: Matcio, Mg: Magnésio,

(04/01/2008), foram realizadas marcações em fileiras de covas espaçadas $0,5 \mathrm{~m}$ e $0,3 \mathrm{~m}$, respectivamente, nas direções secundárias e principal de plantio.

Foi utilizada adubação de cobertura do tipo organomineral em sulcos, oito dias após o transplante. O adubo foi posicionado distando das fileiras de plantas $10 \mathrm{~cm}$ e na profundidade $7 \mathrm{~cm}$. A formulação foi calculada de acordo com a análise de solo (Tabela 1), e seguinda a recomendação de adubação específica, com base em Cavalcanti (2008), não tendo sido necessária a calagem.

Aplicações foliares de cálcio e boro foram realizadas aos 50,58 e aos 67 dias após transplante (DAT) e aplicados $150 \mathrm{~L}$ de calda da solução, dos quais $0,375 \mathrm{~L}$ foram do produto comercial CAB10 que contém, em sua composição $0,08 \mathrm{~L}$ de cálcio e $0,02 \mathrm{~L}$ de boro, conforme recomenda Filgueira (2007).

Realizaram-se capinas periódicas combinando-se os métodos mecânico e manual, visando controlar ervas invasoras. A cobertura morta utilizada foi de capim elefante, da variedade "Roxo de Botucatu",com $3 \mathrm{~cm}$ de espessura média e densidade de $13 \mathrm{Mg} \mathrm{ha}^{-1}$, mesma espessura utilizada por Queiroga et al. (2002). A colheita foi realizada aos 83 DAT.

As umidades do solo foram avaliadas de acordo com a metodologia de Souza et al. (2008a), que utilizaram sonda de nêutrons tipo 503 DR HYDROPROBE ${ }^{\circledR}$. Adotaram-se médias de umidade do solo na camada de $0-40 \mathrm{~cm}$ e se realizaram 15 medições regularmente distribuídas no decorrer do período experimental. As medições de umidade foram conduzidas antes das irrigações, em tubos de acesso de PVC, de $75 \mathrm{~mm}$ de diâmetro, tendo-se adotado três tubos de PVC por tratamento.

\section{Eficiência de uso da água}

Determinou-se a eficiência do uso da água, definida como quantidade de água consumida para produzir uma unidade de matéria vegetal, podendo ser expressa pela Eq. 2 (Costa et al., 2005):

$$
\mathrm{EUA}=\frac{\mathrm{X}}{\mathrm{Y}}
$$

em que:

EUA - eficiência de uso da água, $\mathrm{Mg} \mathrm{ha}^{-1} \mathrm{~mm}^{-1}$;

$\mathrm{X}$ - produtividade da cultura, $\mathrm{Mg} \mathrm{ha}^{-1}$;

Y - Lâmina de água adotada no manejo da cultura durante o ciclo, em mm.

Para a análise da eficiência do uso da água dividiu-se a produtividade média de cada tratamento pelo consumo hídrico, durante o ciclo da cultura.

O índice de formato de cabeças foi calculado através da relação entre diâmetro vertical de cabeças e diâmetro horizontal, conforme Moura et al. (2006).
As variáveis analisadas foram produtividade de cabeças de repolho (Pr), peso médio de cabeças (PMC), diâmetro vertical de cabeça (DVC), diâmetro horizontal de cabeça (DHC) e índice de formato de cabeça (IFC). Tais variáveis foram determinadas a partir da colheita nas duas fileiras centrais.

\section{Análise estatística}

Foram realizados análise de variância, teste $\mathrm{F}$, e o teste de comparação entre médias (Tukey) a nível de 5\% de probabilidade. Utilizou-se o SAS (SAS Institute, 1999). As variáveis analisadas quanto à interação pelo teste $\mathrm{F}$ foram: I(12)-intervalo de irrigação de 12 h; I(24)-intervalo de irrigação de 24 h; I(48)-intervalo de irrigação de 48 h; COM- presença de cobertura morta e SEM-ausência de cobertura morta. Os fatores foram submetidos a desdobramentos para verificação do efeito isolado de cada um deles, conforme Cardoso et al. (2004), Moraes et al. (2006) e Lima et al. (2006).

\section{RESULTADOS E DISCUSSÃO}

A Figura 2 apresenta a variação temporal de umidade média dos tratamentos, podendo-se observar a variabilidade mais acentuada no tratamento SEMI3. Os tratamentos de manejo com cobertura morta produziram umidade relativamente estável, durante o período experimental, suprindo adequadamente a demanda hídrica exigida pela cultura, independentemente dos intervalos de irrigação com cobertura morta utilizados COMI1, COMI2 e COMI3. Essas umidades medidas sofreram variações de 18,$68 ; 18,45$ e $13,59 \%$, respectivamente, durante o ciclo do cultivo experimental (Figura 2A), as quais não interferiram sobre as variáveis analisadas. Do mesmo modo, os tratamentos SEMI1 e SEMI2 (Figura 2B) possibilitaram condições para atendimento da demanda hídrica das plantas, com variação de valores de umidades durante o ciclo de cultivo de 18,33 e 17,57\%, sem, contudo, influenciar as variáveis analisadas.

Por outro lado, esta variação atingiu o valor de $30,57 \%$ no caso do tratamento (SEMI3), provocando redução significativa nas variáveis Pr e EUA, para as condições do presente experimento, constatando-se sensibilidade do repolho ao déficit de umidade. $\mathrm{O}$ referido resultado está de acordo com Filgueira (2007) e Imtiyaz et al. (2000), os quais afirmam que o repolho exige condições de umidade estável e com reduzida variação, devendo o solo ser mantido com cerca de $80 \%$ da água disponível para atender à demanda hídrica da cultura, sem ocasionar perda de produtividade. No presente estudo, o tratamento SEMI3 proporcionou maior drenagem devido à lâmina aplicada ser mais elevada, tendo perdido água para a atmosfera pela maior exposição da superfície à radiação solar entre irrigações sucessivas, acarretando variação elevada na umidade, a ponto de provocar perda de produtividade. 


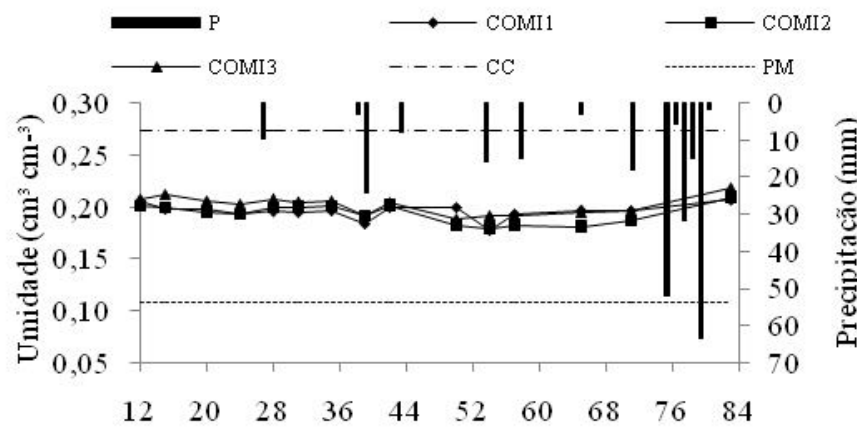

Dias apóstransplante

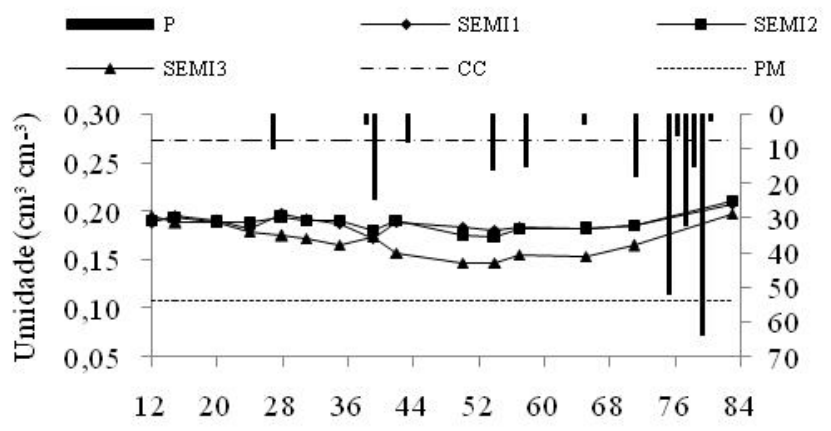

Dias apóstransplante

Figura 2. U midade do solo medida na camada de 0 a $40 \mathrm{~cm}$ de profundidade. $(A)$ precipitaçäo $(P)$; intervalo de irrigação de $12 \mathrm{~h}$ com cobertura morta (CO MI1); intervalo de irrigação de $24 \mathrm{~h}$ com cobertura morta (CO M I2); intervalo de irrigação de 48 h com cobertura morta (CO M I3); capacidade de campo (CC); ponto de mucha (PM ); (B) intervalo de irrigação de $12 \mathrm{~h}$ sem cobertura morta (SEM I1) e intervalo de irrigação de $24 \mathrm{~h}$ sem cobertura morta (SEM I2); intervalo de irrigação de $48 \mathrm{~h}$ sem cobertura morta (SEM I3)

A Pr e a EUA foram influenciadas significativamente pelos intervalos de irrigação e pela presença da cobertura do solo. $\mathrm{O}$ PMC também foi influenciado significativamente pelo uso da cobertura do solo. As demais variáveis não sofreram influência estatística das condições a que foram submetidas nesta pesquisa (Tabela 2). A Pr do I(12) diferiu estatisticamente em relação aos intervalos I(24) e I(48), com diferenças de 3,31 e $6,26 \mathrm{Mg} \mathrm{ha}^{-1}$, respectivamente, assim como a EUA no I(12) diferiu estatisticamente em relação aos I(24) e I(48), em 9,58 e $7,97 \mathrm{Mg} \mathrm{ha}^{-1}$, respectivamente (Tabela 2). Constata-se o efeito positivo de menores intervalos de irrigação. Este comportamento é semelhante ao encontrado por Fracaro et al. (1999) e Montenegro et al. (2004). Assim, o manejo adotado contribuiu para melhorar as condições de produtividade e a eficiência do uso da água, requerido para Pr, PMC, DHC, DVC, IFC e EUA, além de disponibilizar água para as culturas, e aumentar a umidade.

A variação da umidade do solo constitui fator limitante para a cultura do repolho no aspecto da produtividade e eficiência do uso da água. Geralmente, para que seu cultivo se torne viável em condições adversas e se obtenha produtividade acima de 50,00 $\mathrm{Mg} \mathrm{ha}^{-1}$, faz-se necessário o controle desse fator (Filgueira, 2007). Verifica-se que as produtividades foram adequadas (Tabela 2) e superiores às obtidas por Santiago (2002), Araújo et al. (2003) e Moura et al. (2006).

A presença da cobertura morta induziu a aumentos de 2,41 $\mathrm{Mg} \mathrm{ha}^{-1}$ de Pr, 6,87 Mg ha-1 $\mathrm{mm}^{-1}$ de EUAe 108,82 $\mathrm{g} \mathrm{de} \mathrm{PMC,} \mathrm{em}^{-}$ relação ao cultivo na ausência de cobertura morta (Tabela 2). Vários fatores devem ter contribuído, de forma conjunta, para tais diferenças, dentre eles: fornecimento de nutrientes, melhoria da estrutura do solo, maior aeração, redução da incidência direta da luz solar sobre a superfície do solo, conservação da umidade e formação de um microclima favorável, proporcionando crescimento mais rápido das plantas para cobrir mais rapidamente o solo (Resende et al., 2005; Stone et al., 2006). Do mesmo modo, Cassol et al. (2004) e Souza et al. (2008a) destacam que a presença de resíduos vegetais mantém a umidade do solo elevada e aumenta a infiltração. Já Resende et al. (2005) ressaltam que a cobertura morta de origem vegetal exerce papel fundamental sobre o controle de ervas daninhas e sobre a produtividade de olerícolas. Moreira et al. (2004) e Bezerra \& Cantalice (2006) afirmam que a cobertura morta proporciona maior infiltração, maior retenção de água de irrigação e da chuva pelo solo, redução das perdas de água por evaporação, aumento da eficiência de seu uso, sendo essa água melhor aproveitada pelas plantas.

O PMC também sofreu efeito positivo da cobertura morta. Por outro lado, os intervalos de irrigação não influenciaram o PMC. Verifica-se que os valores aqui encontrados são superiores àqueles de Ambrósio \& Moura (1999), Araújo et al. (2003) e Moura et al. (2006). Por sua vez, os valores do presente estudo se assemelham aos de Aquino et al. (2005). Igualmente, os valores obtidos também foram inferiores aos obtidos por Cardoso et al. (2004), que produziram cabeças com massa fresca média de $1056 \mathrm{~g}$ em cultivo de híbridos. Embora os valores de peso médio de cabeças do presente estudo estejam levemente abaixo dos valores recomendados para comercialização $(1 \mathrm{~kg})$, tal redução não compromete sua aceitação no mercado local.

Os coeficientes de variação (CV's) dos tratamentos utilizados apresentaram variação conforme a sensibilidade de cada

Tabela 2. M édias do desdobramento da produtividade e suas variáveis relacionadas, em função dos intervalos de irrigação e do uso da cobertura morta

\begin{tabular}{|c|c|c|c|c|c|c|}
\hline Tratamento & $\begin{array}{c}\mathrm{Pr} \\
\left(\mathrm{Mg} \mathrm{ha}^{-1}\right)\end{array}$ & $\begin{array}{l}\text { PMC } \\
\text { (g) }\end{array}$ & $\begin{array}{l}\text { DHC } \\
(\mathrm{cm})\end{array}$ & $\begin{array}{l}\text { DVC } \\
(\mathrm{cm})\end{array}$ & IFC & $\begin{array}{c}\text { EUA } \\
\left(\mathrm{Mg} \mathrm{ha}^{-1} \mathrm{~mm}^{-1}\right)\end{array}$ \\
\hline I (12) & $37,50 \mathrm{a}$ & $882,41 \mathrm{a}$ & $14,71 \mathrm{a}$ & $8,50 \mathrm{a}$ & $0,64 a$ & $106,88 \mathrm{a}$ \\
\hline I (24) & $34,19 \mathrm{~b}$ & $877,35 a$ & $13,14 a$ & $8,78 a$ & $0,68 a$ & $97,30 \mathrm{~b}$ \\
\hline I (48) & $31,24 \mathrm{~b}$ & 811,00 a & $12,87 \mathrm{a}$ & $8,53 a$ & $0,66 a$ & $88,91 \mathrm{~b}$ \\
\hline COM & $35,53 \mathrm{a}$ & 911,33 a & $14,20 \mathrm{a}$ & $8,68 \mathrm{a}$ & $0,68 \mathrm{a}$ & 101,13 a \\
\hline SEM & $33,12 b$ & $802,51 b$ & $12,95 \mathrm{a}$ & $8,53 a$ & $0,66 \mathrm{a}$ & $94,26 \mathrm{~b}$ \\
\hline
\end{tabular}

Médias seguidas de mesma letra na mesma coluna não diferem entre intervalos de irrigação e presença ou ausência de cobertura morta, pelo teste de Tukey, a $5 \%$ de probabilidade. I(12): intervalo de irrigação de $12 \mathrm{~h}, \mathrm{I}(24)$ : intervalo de irrigação de $24 \mathrm{~h}, \mathrm{l}(48)$ : intervalo de irrigação de $48 \mathrm{~h}$, COM: presença de cobertura morta, SEM: ausência de cobertura morta 
Tabela 3. M édias de produtividade, de variáveis relacionadas e de umidade média em função dos tratamentos aplicados, e de condutividade elétrica média no perío do de cultivo

\begin{tabular}{|c|c|c|c|c|c|c|c|}
\hline \multirow{2}{*}{ Variável } & \multicolumn{7}{|c|}{ Tratamentos } \\
\hline & COMI1 & SEMI1 & COMI2 & SEMI2 & COMI3 & SEMI3 & $\mathrm{CV}(\%)$ \\
\hline EUA (Mg ha $\left.{ }^{-1} \mathrm{~mm}^{-1}\right)$ & $110,49 a$ & $103,27 a$ & $96,31 a b$ & $98,29 a b$ & $96,61 \mathrm{ab}$ & $81,21 b$ & 8,00 \\
\hline $\operatorname{Pr}(\mathrm{Mg})$ & $38,83 a$ & $36,29 a$ & $33,84 a b$ & $34,54 a b$ & $33,95 a b$ & $28,54 \mathrm{~b}$ & 8,00 \\
\hline $\mathrm{PMC}(\mathrm{cm})$ & 933,22 a & $831,60 \mathrm{a}$ & $927,20 \mathrm{a}$ & $827,50 \mathrm{a}$ & $873,58 \mathrm{a}$ & 748,43 a & 10,04 \\
\hline $\mathrm{DHC}(\mathrm{cm})$ & $16,43 a$ & $12,99 \mathrm{a}$ & $12,94 \mathrm{a}$ & $13,33 \mathrm{a}$ & 13,21 a & $12,54 \mathrm{a}$ & 17,34 \\
\hline $\mathrm{DVC}(\mathrm{cm})$ & $8,68 \mathrm{a}$ & $8,34 a$ & $8,65 a$ & $8,91 \mathrm{a}$ & $8,71 \mathrm{a}$ & $8,36 a$ & 13,12 \\
\hline IFC & $0,63 a$ & $0,64 a$ & $0,68 a$ & 0,67 a & $0,66 \mathrm{a}$ & $0,67 a$ & 8,06 \\
\hline M20 & $0,18 a b$ & $0,17 a b$ & $0,17 a b$ & $0,19 a$ & $0,19 a$ & $0,15 b$ & 10,03 \\
\hline M40 & $0,21 \mathrm{a}$ & $0,18 \mathrm{a}$ & $0,20 a$ & $0,21 \mathrm{a}$ & $0,21 \mathrm{a}$ & $0,18 \mathrm{a}$ & 11,39 \\
\hline M20CE & $1,81 \mathrm{ab}$ & $2,19 a$ & $1,63 b$ & $2,19 a$ & $1,76 a b$ & $2,05 a b$ & 11,83 \\
\hline M4OCE & $1,67 \mathrm{~b}$ & $1,88 a b$ & $1,67 \mathrm{~b}$ & $1,98 a b$ & $1,81 \mathrm{ab}$ & $2,10 a$ & 10,27 \\
\hline
\end{tabular}

Médias seguidas de letras iguais, nas linhas, não diferem entre si pelo teste de Tukey a 5\% de probabilidade; Var: variáveis, CoMI1- intervalo de irrigação de $12 \mathrm{~h}$ com cobertura morta; CoMI2- intervalo de irrigação de $24 \mathrm{~h}$ com cobertura morta; COMI3- intervalo de irrigação de $48 \mathrm{~h}$ com cobertura morta; SEMI1- intervalo de irrigação de $12 \mathrm{~h}$ sem cobertura morta; SEMI2- intervalo de irrigação de $24 \mathrm{~h}$ sem cobertura morta; SEMI3-intervalo de irrigação de $48 \mathrm{~h}$ sem cobertura morta; EUA- eficiência do uso da água; Pr- produtividade média de cabeças de repolho; PMC- peso médio de cabeças; DVC- diâmetro médio vertical de cabeça; DHC- diâmetro médio horizontal de cabeça; e IFC- índice médio de formato de cabeça; M20- médias de umidade do solo de 0-20 cm de profundidade; M40médias de umidade do solo de $20-40 \mathrm{~cm}$ de profundidade; M20CE- médias de condutividade elétrica do solo 0-20 cm de profundidade; M40CE- médias de condutividade elétrica do solo $20-40 \mathrm{~cm}$ de profundidade

variável analisada sob as condições às quais foram submetidas (Tabela 3), podendo ser considerados baixos. Esses resultados mostram o controle adequado da homogeneidade dentro dos blocos e dos tratamentos, o controle no momento da coleta dos dados dessas variáveis, o autoajuste do sistema de irrigação e da cobertura morta em sua uniformidade, tal como a uniformidade de aplicação da irrigação, e das próprias plantas no momento do transplante e da aplicação de adubos.

Os CV's do presente estudo são inferiores àqueles de Moura et al. (2006), que encontraram valores de 6,2, 25,8 e 25,9\% para as variáveis IFC, PMC e Pr, respectivamente. Cardoso et al. (2004) também encontraram CV's superiores aos do presente estudo. O valor do CV indicado por Moraes et al. (2007), avaliando a média de diâmetro de cabeças na variedade 'chato de quintal' em Dourados, MS, foi de 12,27\%. Já Nunes et al. (2004) apontaram, em Estância, SE, CV's para peso de cabeça e produtividade de 22,65 e $22,65 \%$, respectivamente. Essa variação pode está condicionada às diferenças do local de cultivo e entre cultivares utilizadas. O CV para DHC e DVC (Tabela 3) apresentou maior variação quanto aos encontrados por Moraes et al. (2007). O CV da EUA foi semelhante aos CV's das variáveis Pr e IFC, respectivamente.

No turno de rega de dois dias, a umidade da camada superficial de $20 \mathrm{~cm}$ foi sensivelmente influenciada pela presença da cobertura morta. Não se nota influência da cobertura morta na umidade da camada $40 \mathrm{~cm}$. O manejo do tratamento SEMI3 corrobora com o aumento da salinidade na profundidade a $40 \mathrm{~cm}$.

De modo geral, todos os tratamentos proporcionaram resultados satisfatórios quanto à produtividade, eficiência do uso da água e suas variáveis relacionadas (Tabela 3); verificouse, porém, que o tratamento sem cobertura morta com intervalo de irrigação de quarenta e oito horas (SEMI3) foi menos eficiente em relação aos demais tratamentos, para as variáveis EUA e Pr, uma vez que a cultura do repolho é influenciada pelas variações de umidade e práticas de manejo já mencionados em parágrafos anteriores. As demais variáveis não foram influenciadas a ponto de diferirem estatisticamente (Tabela 3). A Pr e a EUA sofreram esses efeitos, que podem ser confirmados ao se verificar a média de umidade do solo de $0-20 \mathrm{~cm}$ de profundidade no tratamento sem cobertura morta com intervalo de irrigação de quarenta e oito horas (SEMI3), que foi estatisticamente menor. Verifica-se a relevância de se adotar a cobertura morta no tratamento com intervalo de irrigação de quarenta e oito horas (COMI3), possibilitando eficiências de uso e produtividades compatíveis com as obtidas a partir de intervalos de irrigação de vinte e quatro horas, com presença e ausência de cobertura morta (COMI2 e SEMI2).

\section{CONCLUSÕES}

1. Para as condições estudadas, a utilização de intervalo de irrigação de doze horas com cobertura morta proporcionou maior eficiência do uso da água e maior produtividade de repolho, quando comparadas aos demais tratamentos.

2. O uso da cobertura morta proporcionou maior média de peso de cabeças de repolho, permitindo ao agricultor maior rentabilidade.

3. Quando se analisou o efeito combinado da cobertura morta e do intervalo da irrigação, verificou-se que a ausência da cobertura no manejo da irrigação 48 horas reduziu tanto a eficiência do uso da água quanto a produtividade do repolho, para as condições edafoclimáticas estudadas.

\section{Agradecimentos}

Os autores agradecem o apoio do CT-Hidro/CNPq, pela concessão da bolsa de mestrado do primeiro autor; agradecem também pelo financiamento do projeto às Instituições já citadas, à FINEP e à FACEPE.

\section{LITERATURA CITADA}

Ambrósio, F. J.; Moura, M. C. C. L. Avaliação de híbridos experimentais e comercial de repolho para a Ilha de São Luís-MA. Pesquisa em Foco, v.7, p.7-16, 1999. 
Aquino, L. A.; Puiatti, M.; Pereira, P. R. G.; Pereira, F. H. F.; Castro, M. R. S.; Ladeira, I. R. Características produtivas do repolho em função de espaçamentos e doses de nitrogênio. Horticultura Brasileira, v.23, p.266-270, 2005.

Araújo, J. C.; Moura, E. G.; Cantanhêde, I. S. L.; Resende, F. A. Produtividade e qualidade do repolho submetido a várias lâminas d'água e turnos de rega na irrigação por sulco fechado. Horticultura Brasileira, v.21, p.346-351, 2003.

Ayers, R. S.; Westcot, D. W. A qualidade da água na agricultura. Campina Grande: UFPB, 1991. 218p. FAO. Estudos de Irrigação e Drenagem, 29

Bezerra, S. A.; Cantalice, J. R. B. Erosão entressulcos em diferentes condições de cobertura do solo, sob o cultivo da cana-de-açúcar. Revista Brasileira de Ciência do Solo, v.30, p.565-573, 2006.

Brackmann, A.; Trevisan, J. N.; Martins, G. A. K.; Freitas, S. T.; Mello, A. M. Etileno, 1-metilciclopropeno e qualidade de repolho cv. wakaba armazenado em ambiente refrigerado. Revista Brasileira de Agrociência, v.9, p.403-405, 2003.

Cardoso, M. O.; Moura, M. F.; Oliveira, A. P. Produção e teores de macronutrientes em função de cultivares, espaçamentos e níveis residuais de fósforo e cálcio em repolho. Horticultura Brasileira, v.22, CD-Rom, 2004.

Cassol, E. A., Cantalice, J. R. B.; Reichert, J. M.; Mondardo, A. Escoamento superficial e desagregação do solo em entressulcos em solo franco-argilo-arenoso com resíduos vegetais. Pesquisa Agropecuária Brasileira, v.39, p.685-690, 2004.

Cavalcanti, F. J. A. Recomendações de adubação para o Estado de Pernambuco. 3.ed. Recife: Instituto Agronômico de Pernambuco - IPA, 2008. 212p.

Costa, R. N. T.; Colares, D. S.; Saunders, L. C. U.; Souza, F. Análise das eficiências de aplicação e de uso da água em cultivo de arroz no Perímetro Irrigado Morada Nova Ceará. Irriga, v.10, p.372-382, 2005.

Doorenbos ,J. Kassam, A. H. Efectos del água em al rendimiento de los cultivos. Roma: FAO 1979. p.212.

EMBRAPA - Empresa Brasileira de Pesquisa Agropecuária. Manual de métodos de análise de solo. 2ed. Rio de Janeiro: Ministério da Agricultura e do Abastecimento, 1997. 212p.

Filgueira, F. A. R. Novo manual de olericultura: agrotecnologia moderna na produção e comercialização de hortaliças. 3.ed. Viçosa: UFV, 2007. 421p.

Fracaro, F.; Sartori, M.; Bizzani, E.; Grelman, E.; Echeverrigaray, S. Comportamento agronômico de cultivares e híbridos de repolho na região Nordeste do Rio Grande do Sul. Ciência Rural, v.29, p.465-468, 1999.

Genuchten, M. T. van. A closed-form equation for predicting the hydraulic conductivity of unsaturated soils. Soil Science Society of America Journal, v.44, p.892-898, 1980.

Imtiyaz, M.; Mgadla, P. N.; Manase, S. K.; Chendo, K.; Mothobi, E. O. Yield and economic return of vegetable crops under variable irrigation. Irrigation Science, v.19, p.87-93, 2000.

Lédo, F. J. S.; Souza, J. A.; Silva, M. R. Avaliação de cultivares e híbridos de repolho no Estado do Acre. Horticultura Brasileira, v.18, p.138-140, 2000.
Lima, P. A.; Montenegro, A. A. A.; Lira Jr., M. A.; Santos, F. X.; Pedrosa, E. M. R. Efeito do manejo da irrigação com água moderadamente salina na produção de pimentão. Revista Brasileira de Ciências Agrárias, v.1, p.73-80, 2006.

Maas, E. V. Salt Tolerance of Plants. Applied Agricultural Research, v.1, p.12-26, 1986.

Montenegro, A. A. A.; Montenegro, S. M. G. L. Variabilidade espacial de classes de textura, salinidade e condutividade hidráulica de solos em planície aluvial. Revista Brasileira de Engenharia Agrícola e Ambiental, v.10, p.30-37, 2006.

Montenegro, S. M. G. L.; Montenegro, A. A. A.; Ragab, R. Improving agricultural water management in the semi-arid region of Brazil: Experimental and modelling study. Irrigation Science, v.28, p.301-316, 2010.

Montenegro, S. M. G. L.; Silva, K. C. M.; Montenegro, A. A. A. Avaliação do manejo da irrigação por microaspersão da cultura do repolho em região semi-árida. In: Simpósio de Recursos Hídricos do Nordeste, 7, 2004, São Luis. Resumos... São Luís: SRHN, 2004.

Moraes, A. A.; Vieira, M. C.; Zárate, N. A. H. Produção de repolho chato de quintal e da capuchinha jewel, solteiros e consorciados, sem e com cama-de-frango semidecomposta incorporada no solo. Ciência Agrotécnica, v.31, p.731-738, 2007.

Moreira, J. A. A.; Cánovas, A. D.; Stone, L. F. Determinação do consumo de água para cultura de grãos no sistema plantio direto com diferentes níveis de cobertura do solo: coeficiente de cultura. Santo Antonio de Goiás: Embrapa Arroz e Feijão, 2004. 8p.

Moura; E. G; Rezende, K. D. A.; Araújo, J. C.; Castro, M. F. Efeito de métodos de irrigação e do uso de cobertura vegetal sobre o cultivo de repolho em São Luís-MA. Horticultura Brasileira, v.24, n.4, p.410-413, 2006.

Mulumba, L. N.; Lal, R. Mulching effects on selected soil physical properties. Soil \& Tillage Research, v.98, p.106111, 2008.

Nunes, M. U. C.; Andrade, L. N. T.; Moraes Filho, M.; Cunha, A. O.; Mata, S. S. Comportamento de cultivares de repolho em sistema orgânico de produção. Horticultura Brasileira, v.22, n.2, 2004. CD-ROM

Queiroga, R. C. F.; Nogueira, I. C. C.; Bezerra Neto, F.; Moura, A. R. B.; Pedrosa, J. F. Utilização de diferentes materiais como cobertura morta do solo no cultivo de pimentão. Horticultura Brasileira, v.20, p.416-418, 2002.

Ragab, R. A holistic generic integrated approach for irrigation, crop and field management: The SALTMED model. Environ Model Software, v.17, p.345-361, 2002.

Resende, F. V.; Souza, L. S.; Oliveira, P. S. R.; Gualberto, R. Uso de cobertura morta vegetal no controle da umidade e temperatura do solo, na incidência de plantas invasoras e na produção da cenoura em cultivo de verão. Ciência Agrotécnica, v.29, n.1, p.100-105, 2005.

Rhoades, J. D. Drainage for salinity control. In: van Schilfgaarde, J. (ed.). Drainage for agriculture. Madison: American Society of Agronomy, 1974, p.433-462. 
Santiago, F. S. Efeito do manejo da irrigação na salinidade e umidade de um Neossolo Flúvico, com a cultivar de repolho midori no município de Pesqueira. Recife: UFRPE, 2002. 84. Dissertação Mestrado

Santiago, F. S.; Montenegro, A. A. A.; Montenegro, S. M. G. L. Avaliação de parâmetros hidráulicos e manejo da irrigação por microaspersão em área de assentamento. Engenharia Agrícola, v.24, n.3, p.632-643, 2004.

SAS Institute. The SAS system for Windows. Cary, SAS Institute, 1999, CD-Rom.
Souza, E. R.; Montenegro, A. A. A. Freire, M. B. G. S. Evolução e variabilidade espacial da salinidade em Neossolo Flúvico cultivado com cenoura sob irrigação, Revista Brasileira de Engenharia Agrícola e Ambiental, v.12, n.6, p.584-592, 2008b

Souza; E. R; Montenegro, A. A. A.; Montenegro, S. M. G. L. Variabilidade espacial da umidade do solo em Neossolo Flúvico. Revista Brasileira de Recursos Hídricos, v.13, n.2, p. 177-187, 2008a. Stone, L. F.; Silveira, P. M.; Moreira, J. A. A.; Pereira Braz, A. J. B. Evapotranspiração do feijoeiro irrigado em plantio direto sobre diferentes palhadas de culturas de cobertura. Pesquisa Agropecuária Brasileira, v.41, n.4, p.577-582, 2006. 